\title{
Business Localization Problems in Rural Areas
}

\author{
Assoc. Prof. PhD Teodorina Turlakova \\ University of Economics - Varna, Varna, Bulgaria \\ tturlakova@ue-varna.bg
}

\begin{abstract}
The article examines two of the most widely used methods of region assessment. It is based on the understanding that the choice of the entrepreneur for the location of the business should not be based on intuitive but objective prerequisites. They derive from the right mix between natural and socio-economic characteristics of the region and the specifics of the emerging business. The classification method for the types of evolution of the regions assumes the use of several indicators: production, employment and productivity of the region. Despite its clarity, its application is related to some difficulties and disadvantages which are shown in the article. The Shift and Share Analysis method is reviewed in greater detail, which application and results are demonstrated by an examination over Dobrich area.
\end{abstract}

Keywords: locational choice, assessment of the region, evolution of the region, Shift and Share Analysis

JEL Code: R12; doi:10.36997/IJUSV-ESS/2019.8.1.202

\section{Въведение}

Локалното развитие протича в руслото на две на пръв поглед противоречиви тенденции - хомогенизация и диференциация. От една страна, глобалните и национални тенденции се проектират в реален, специфичен от гледна точка на историческите дадености, традиции и култура конкретен национален контекст. От друга страна, общите процеси, протичащи в конкретно общество, имат регионална, местна проекция в периметьра на основните регионални единици.

Изследването на локалността в различните й измерения е начин да се оцени специфичното, особеното и чрез него да се създадат условия за превръщане на дадено място в културно-устойчива среда. Търсенето на възможности за местно развитие ориентира изследователското ни внимание към анализ на социално-икономическото развитие на районите с оглед конструиране на система от бизнес отношения. Разглеждането на бизнеса и предприемаческата дейност като основна част от тази цялост произтича от няколко основни причини.

Основната е свързана с иманентната същност на предприемаческата инициатива да търси и открива потенциалните възможности за комбиниране на ресурси на местно равнище.

Локализационният избор на предприемачите е сложен процес, в който обективизирането на действията предполага използването на различни методи за анализ. Изследователят следва да подбере конкретния метод в зависимост от вида на резултатите, до които се опитва да достигне.

Целта на настоящото изложение е да се изяснят някои приложни методи за анализ на социално-икономическото и технологично състояние на района (придобили широка популярност сред предприемачите в западноевропейските страни), които са количествен инструментариум за локализационен избор на предприемачите и средство за изграждане на регионални стратегии и програми.

\section{1.Характеристика на алтернативните методи за оценка на районите}

Популярна предприемаческа рамка, която се ползва от политиците за формулиране на регионални мерки за развитие на предприемачеството е представената от Јау Каупе фигура на работна сесия на Фондацията «Кауфман» в Рочер, Минесота (Kayne,2000). В нея са представени практически стъпки по въвеждане на определени политики и мерки за развитие 
на предприемачеството. На първи етап в предприемаческата рамка авторьт предлага да се изследва склонността на населението към предприемачество. В случай, че склонността не е на високо равнище следва да се предприемат политики, програми или мерки за създаване на подходяща предприемаческа култура и поведение на населението в района. На следващия етап се проверява наличието на подходящо образование, знания и умения сред жителите на района. Отрицателните резултати следва да ориентират местните власти към програми и мерки за обучение в различни направления. В последния етап въпросите в предприемаческата рамка са насочени към успеха на предприемаческата дейност и имат за цел да предложат програми и мерки подкрепящи растежа на фирмите.

Съществуват и редица практически примери за политически решения в сферата на насърчаване на предприемачеството в селските райони. В Националната териториална стратегия на Ирландия, например разработената национална рамка за планиране за периода 2002-2020 включва разпространението на предприемачеството в селата и малките градчета. Тя препоръчва следните характеристики на предприемачеството като подходящи елементи на политиката на селските райони:

1. Естеството и предмета на дейност на предприятието трябва да са подходящи за района в икономическо, социално и екологично отношение. Като правило трябва да се избягва местоположението на прекалено големи предприятия в селските райони.

2. Политиките по създаване на предприятия трябва да бъдат гъвкави и да са в посока на улесняване на местните обстоятелства;

3. Политиките по отношение на предприятията в селските райони и малките градове трябва да се разглеждат в интегриран пакет.

4. Необходимо е селските предприятия да се насочат не само в сферата на туризма като алтернатива на земеделието, а да се търсят и други възможни алтернативи.

В докладите на ОИСР също се препоръчва развитие на правителствени политики за създаване и развитие на малки и средни предприятия (МСП) за съживяване на селските райони. По-конкретните препорьки в докладите се свеждат до:

- Създаване на ефективни и безпристрастни финансови пазари за МСП;

- Изграждане на бизнес среда за предприятията в селските райони;

- Предлагане на постоянно образование, обучение с цел да се създадат възможности за конкуренция между МСП в региона;

- Да се увеличи достъпа до информация за световния пазар, включително и чрез информационни мрежи.

Напоследък, добрите практики в други страни (например Китай) показват, че за развитие на региона са важни не само програми за стартиране на бизнес, но преди всичко за т.нар."заврьщащи се предприемачи" .

Присъщата гъвкавост на предприемаческите структури ги прави изключително подходящи за развитие на регионите, които са много разнообразни по своята характеристика. Не трябва да се подценява и обратната връзка, а именно влиянието на предприемачеството върху развитието на региона чрез подпомагане на местни социални инициативи, екологични практики, създаване на предприемачески мрежи, които да реализират положителна промяна в селската икономика.

Като подходящ и лек за ползване може да се отбележи методът за класификация на типовете еволюция, наблюдавана в регионите, разработена от проф. Р.Камани от Търговския университет в Милано. Комбинирайки представените чрез съответните коефициенти характеристики за нарастване на производството, заетостта и производителността в региона, той обособява седем типа еволюция:

- Еволюция, при която нарастването на производителността, заетостта и производството е по-голямо от средното за страната. Подобна еволюция се наблюдава в районите с динамични взаимоотношения, т.е. райони, които се обновяват. В същото време 
подобна еволюция е присъща и за някои изостаналите райони, предимно със селскостопанска ориентация и намиращи се в период на модернизация. Подобни региони, авторът назовава региони от т.нар. «добродетелен кръг»;

- Еволюция, при която нарастването на производителността и производството са над средното равнище, а вътрешната заетост намалява до средното за страната ниво. В случая регионите се развиват повече за сметка на преобразуването на съществуващи, отколкото чрез създаване на нови дейности;

- Промяна (еволюция), при която производителността и продукцията растат по-бързо от средната база за сравнение, но и заетостта намалява по-бързо. Развитието на тези региони се дължи на преструктуриране на дейностите;

- Еволюция, при която производителността нараства по-бързо от средната за страната, производството едва се увеличава, а заетостта спада по-бързо. Тази еволюция е свойствена на централните региони, които пристъпват към ликвидиране на регресивни дейности с цената на висока безработица;

- Еволюция, при която трите индикатора имат стойности по-ниски от средните за страната. Наблюдава се в районите на деиндустриализация - относителна и абсолютна.

- Еволюция, свързана с по-бавно нарастване на производителността и производството в сравнение със средните за страната индикатори, но и заетостта намалява по-бавно. Регионът се характеризира с индустриален консерватизъм, при който отказването от преструктуриране ограничава решаването на проблемите за заетостта с цената на слаб технологичен динамизъм;

- Еволюция, при която производителността нараства по-бавно, а производството и заетостта - по-забележимо, отколкото обикновено.Налице е реален технологичен динамизъм, съпроводен с посредствена производителност.

Таблица 1. Типове райони по еволюцията на показателите за МСП

\begin{tabular}{|c|c|c|c|c|c|}
\hline \multirow[t]{2}{*}{ Планов район } & \multicolumn{3}{|c|}{$\begin{array}{c}\text { Изменение на показателите за } \\
\text { МСП в региона спрямо } \\
\text { показателя за страната } \\
\end{array}$} & \multirow[t]{2}{*}{\begin{tabular}{|c|} 
Характеристика на \\
региона за влияние към \\
МСП
\end{tabular}} & \multirow[t]{2}{*}{$\begin{array}{c}\text { Класификация според } \\
\text { Камани }\end{array}$} \\
\hline & \begin{tabular}{|l|} 
производи \\
телност
\end{tabular} & заетост & приходи & & \\
\hline Северозападен район & $<(-)$ & $>$ & $>$ & $\begin{array}{c}\text { Ликвидират се стари } \\
\text { производства със } \\
\text { затихващи функции } \\
\end{array}$ & $\begin{array}{c}\text { Освобождаващ се от } \\
\text { регресивни дейности район }\end{array}$ \\
\hline Северен централен район & $<$ & $>(+)$ & $>$ & $\begin{array}{l}\text { Процес на промяна в } \\
\text { МСП }\end{array}$ & Преструктуриращ се \\
\hline Североизточен район & $>$ & $>(+)$ & $>$ & $\begin{array}{c}\text { Благоприятен за } \\
\text { разгръщане на } \\
\text { производство } \\
\end{array}$ & Добродетелен \\
\hline Югоизточен район & $<$ & $>(-)$ & $<(-)$ & $\begin{array}{l}\text { Поддържат се } \\
\text { консервативни } \\
\text { дейности }\end{array}$ & Консервативен район \\
\hline Южен централен район & $<$ & $>$ & $>$ & $\begin{array}{l}\text { Избирателно } \\
\text { благоприятен } \\
\end{array}$ & Трансформиращ се \\
\hline Югозападен район & $>(+)$ & $<$ & $<(+)$ & $\begin{array}{c}\text { Ликвидират се стари } \\
\text { производства със } \\
\text { затихващи функции } \\
\end{array}$ & $\begin{array}{c}\text { Освобождаващ се от } \\
\text { регресивни дейности район }\end{array}$ \\
\hline
\end{tabular}

Легенда: знаците > или < означават увеличение или намаление на показателя в динамика, а знаците (+) или (- ) бърза и съответно бавна промяна.

На таблица 1. е направен опит да се приложи класификацията на Камани за плановите региони в България. Данните за обема на производството са заместени с приходите от основна дейност, което е един по-коректен пазарен показател за дейността на фирмите.

Подобна класификация на районите е необходима, за да се изведат основните характеристики на района, на базата на които ще се предприемат подходящи 
директни/индиректни мерки и програми за подкрепа с изразени или без изразени приоритети. Тук следва да отбележим, че подобна оценка може да се окаже практически необходима не само за изготвящите стратегии, програми и мерки за подкрепа. Преди да пристъпи към каквато и да е дейност и особено с висока степен на риск, всеки предприемач предварително се стреми да получи по-пълна и точна информация за обкръжаващата среда, за климата на предприемачество в отделните региони. При провеждане на начални проучвания за инвестиране изключително полезна би била информацията свързана не само с количествените значения на показателите, но и с обща оценка на привлекателността на региона.

Извършването на този анализ ще бъде по-точно, ако са налице две условия:

- Сред системата от показатели се въведе показателят “брутен регионален продукт”. Липсата на този показател затруднява ранжирането на регионите по степента на техния икономически растеж създаван от малкия бизнес.

- Определените планови райони се детайлизират до по-малки единици, които са с относително еднакво ниво на развитие. В определените планови райони се забелязват вътрешнорегионални различия, което се дължи на различното ниво на социалноикономическо развитие в отделни области и общини на плановия район.

Макар и лек за прилагане модельт на еволюцията на Камани съдържа и недостатъци, резултат от вероятната взаимовръзка между производството, броят на заетите и производителността.

От друга страна типологията на регионите може да се обогати и с други показатели и нови комбинации между тях.

При стратегическото проектиране на основните насоки за развитие на даден регион е необходимо да се проведе задълбочено проучване на местните конкурентни предимства. Това са всички сектори и дейности, които се развиват по-ефективно отколкото в други области и райони и които придават облика, характерните черти, лицето на региона.Открояването на конкурентните предимства е важно по две причини. От една страна те образуват ядрото от основни приоритети при разработване на стратегията за местно икономическо развитие. Върху тях обикновено се хвърлят най-много усилия, докато останалите сектори се разглеждат като съпътстващи. Местните конкурентни предимства представляват ендогенните фактори за развитие, върху които могат да се градят местните инициативи. От друга страна, наличието на различни по вид и интензивност конкурентни предимства между районите в една страна води до силни диспропорции и е предпоставка за задълбочаване на пространствените различия (Dunn, E.S:1960). Следователно на тази база следва да се развият политиките на диверсификация на местната икономика.

Подходящ за подобни изследвания е иконометричния метод, известен в литературата като Shift and Share Analysis (Fernandez \&other,2002). В класическия му вариант той се базира на сравнението на достигнатото състояние по избран показател в даден регион с условен показател, при който развитието на секторите в региона се екстраполира на база на средното развитие на съответните сектори в страната.

Прилагането на Shift and Share анализа изисква на първо място да се избере индикатор, който да отразява адекватно икономическото развитие на региона. Най-често използваните индикатори са изменението на брутния регионален продукт на едно лице, прирастьт на доходите на едно лице и т.н. Когато просперитетьт на региона се разглежда в неговия социално-икономически контекст, често използван индикатор е изменението на заетостта. От гледна точка на предприемаческата активност и отражението й върху региона, използването на този показател ще допринесе за търсените резултати от анализа.

Очевидно е, че нарастването на броя на заетите лица е желана цел и очакван резултат за ръководството на всеки регион. Спадът в броя на работните места и респективно-в броя на заетите е сигнал за тежки сътресения с големи социално-икономически и дори политически 
последствия, които могат да имат различни измерения. Обикновено спадът в заетостта е съпроводен с негативни изменения и във всички останали индикатори на развитието, но именно възникващата безработица е проблемът, който изпъква с най-голяма сила. За да се анализира напредъка или изоставането в развитието на даден регион обаче не е достатъчно просто да се посочи броят на увеличените или намалени работни места. Причините за това изменение могат да бъдат различни. В едни случаи те се дължат на фактори с локален характер от най-различно естество, а в други-на общия спад на продуктивността и респективно на заетостта в даден сектор. Именно проучването и декомпозирането на източниците на растежа или спада в даден сектор в региона представляват основното предимство на метода Shift and Share.

Системата за статистическа информация в страната обаче не дава възможност да се проследи броят на заетите по сектори и по райони или области. Ето защо за нуждите на анализа ще бъде използвано изменението на броя на наетите лица по трудово и служебно правоотношение по отраслови сектори на ико номиката. Според възприетата методика на отчитане от НСИ, наетите в даден сектор са част от заетите не само поради включването и на други групи в структурата на заетите лица, но и поради методиката за отчитане на наетите в средногодишен размер. Важно в случая е, че лицата, заети в даден сектор само сезонно, както е например в селското стопанство, са и наети в този сектор, но техният брой като наети е много по-малък от фактическия им брой като заети, тъй като средногодишно те са отработили малък брой дни. В този смисъл използването на броя на наетите по трудово и служебно правоотношение е показател, който е по-подходящ за нуждите на анализа на структурните и пространствени различия на регионалните системи. Той дава възможност да се проследят човекодните отработено време, а не броят на хората, които са извършили дадена работа.

Прилагането на метода Shift and Share Analysis е свързано със сравняване на изменението на фактическия брой наети в региона с ,условното" равнище на наетите, чиито брой е получен при условие, че секторите в региона са се развивали с растеж, равен на този в страната.

Отклонението на фактически наетите от „условно наетите” може да бъде декомпозирано в три основни компонента: национален ефект, структурен ефект (наречен още пропорционален ефект или ефект на индустриалния микс) и локален факторен (localfactor effect) ефект (наречен още конкурентен, пространствен или регионален ефект).

Анализът на структурните и локалните отклонения предоставя информация за товакаква част от изменението на броя на наетите в региона се дължи на общи за страната (структурни) фактори, произтичащи от икономическия растеж на отделните сектори, и каква част се дължи на локални фактори.

При класическия вариант на метода, за определянето на трите компонента на растежа, се изчисляват следните показатели:

- Относителен прираст на наетите в сектор і в регион j.

$\mathrm{r}_{\mathrm{ij}}=\frac{\mathrm{N}_{\mathrm{ij}}^{\mathrm{t}}-\mathrm{N}_{\mathrm{ij}}^{\mathrm{t} 0}}{\mathrm{~N}_{\mathrm{ij}}^{\mathrm{t}}}$

където:

$\mathrm{N}_{\mathrm{ij}}^{\mathrm{t}}$ - брой наети в сектор $\mathrm{i}(\mathrm{i}=1, \ldots \mathrm{S})$ в регион $\mathrm{j}$

$(\mathrm{j}=1, \ldots \mathrm{R})$

$\mathrm{N}_{\mathrm{ij}}^{\mathrm{t}^{\prime}}$-през последната година $\mathrm{t}^{\prime}$ за периода на изследване,

$\mathrm{N}_{\mathrm{ij}}^{\mathrm{t0}}$ - брой наети в сектор i в регион $\mathrm{j}$ през базова година $t 0$. 
- Относителен прираст на наетите в сектор i, като се сумират наетите в регион $(j=1, \ldots R)$ :

$$
r_{i}=\frac{\sum_{j} N_{i j}^{t}-\sum_{j} N_{i j}^{t 0}}{\sum_{j} N_{i j}^{t}}
$$

- Относителен прираст на заетостта в страната през периода на изследване, като се сумират наетите във всички сектори $\mathrm{i}(\mathrm{i}=1, \ldots \mathrm{S})$ във всички региони $(\mathrm{j}=1, \ldots \mathrm{R})$ :

$$
r=\frac{\sum_{i j} N_{i j}^{t}-\sum_{i j} N_{i j}^{t 0}}{\sum_{i j} N_{i j}^{t}}
$$

Посредством трите вида прираст се определят и трите вида ефект:

Националният ефект (C) представлява относителния прираст на броя на наетите в страната през периода на изследване и се изразява чрез уравнение

$\mathrm{C}=\mathrm{r}$

Структурният ефект (S) е разлика между относителния прираст на наетите в сектор i прираста на всички наети в цялата страна.

$$
\mathrm{S}=\mathrm{r}_{\mathrm{i}}-\mathrm{r}
$$

Локалният (пространственият) ефект (R) ce определя като разлика между относителния прираст на наетите в сектор і в регион j и прираста на наетите в сектор i в цялата страна:

$$
R=r_{i j}-r_{i}
$$

Методът Shift and Share Analysis дава възможност да се направят изводи в следните насоки:

- Определяне на онези сектори в региона, при които пространственият ефект е найголям. Тъй като той е резултат от фактори с локален характер, тези сектори се развиват по-добре, отколкото в други области. Регионът привлича предприемачи поради атрактивността си - високо образована работна сила, добре развита инфраструктура, наличие на суровинна база, съществуване на т.нар. „териториални любезности” и т.н. Като цяло тази група фактори определя конкурентноспособността на местната икономика. В същото време определянето на секторите с най-нисък или отрицателен пространствен ефект ще даде обратната информация-в кои сектори регионът е неконкурентноспособен. Когато тази информация се обвърже с възможните причини, анализът ще разкрие необходимо ли е да се полагат усилия за увеличаване на конкурентноспо собността на региона или това няма да е по възможностите на местното ръководство и на бизнеса.

- Анализът на структурния ефект върху развитието на отделните сектори откроява връзката между развитието на сектора в региона и в страната като цяло. При това е от значение локализационният коефициент на сектора, т.е. делът на наетите в областта към общия брой наети в нея, от една страна, и делът на наетите в сектора в страната към общия брой наети. Така структурният ефект, който в относителен размер е еднакъв за всички области в страната, се проявява като различен абсолютен размер на нарастването или намаляването на броя на наетите във всяка област. Той отразява как композицията от отрасли, които вече са се наложили в региона, влияе върху неговия икономически растеж. 
- Общият за региона пространствен ефект е интегрален индикатор за конкурентноспособността на местната икономика. Той би могъл да се използва за сравнение между всички области или райони. Той има отношение и към показателите за типологията на земеделските стопанства в региона (Turlakova,2017).

- Общият структурен ефект показва какво е влиянието на наложилите се вече сектори в региона като отраслов микс, т.е. доколко в региона присъстват по-бързо или по-бавно развиващи се сектори и как те влияят върху абсолютното изменение на заетостта.

\section{2. Приложение на подходите за оценка в област Добрич}

Изчислителните процедури, с които може да се демонстрира използването на метода се базира на данни за заетостта в страната и област Добрич, която е типичен представител на селските райони в страната.

Анализът се базира на два периода- 2010 и 2015 г. Прирастът на заетостта за периода е отрицателен. Това се наблюдава за всички отрасли с изключение на селско,горско и рибно стопанство, добивната промишленост, доставката на вода, транспорт, ресторантъорство и хотелиерство, професионална дейност и научни изследвания.

Някои от секторите (например ресторантъорство и хотелиерство, административни и спомагателни дейности) имат по-висок прираст от средния за страната. Макар и добре развит и типичен земеделски район в Добричка област заетостта в селското стопанство е с по-нисък прираст от средния за страната. Това се дължи и на ниската трудоемкост при производството на зърнени култури в сравнение с други земеделски производства в страната.

Общата редукция в броя на заетите в Добричка област за периода 2010-2015 г. е -0,11 \% или 42 души, което е относително малка величина спрямо показателя за страната в размер на $-1,52 \%$. Забелязва се еднаква тенденция в намаляване на заетостта. Съгласно описаният по-горе иконометричен метод са определени трите вида прираст и съответно трите вида индикатори на ефекта:

- Структурен ефект, с положителен знак и ниво от 2,35 \%. Този \% е относителен дял на сумата от структурните ефекти по сектори.

- Пространствен (локален ефект) - с отрицателна стойност от $-0,94 \%$, като в абсолютна стойност е намаление на заетостта с 375 души в резултат от действието на локални фактори.

Сумата на трите компонента е $-0,11 \%$, т.е. трите индикатора съвместно действат в негативна посока.

Следователно общото намаление на броя на заетите в района се дължи преди всичко на негативното действие на национални и местни фактори. Структурните фактори, а именно наложилата се в района композиция от сектори има не много силно, но положително влиние върху заетостта.

Така например за селското стопанство (код А от НКИД 2008) могат да се изчислят следните индикатори за периода 2010-2015 г.Прирастьт е от 215 души, който е резултат от:

- Национален ефект в размер на намаление с -73 души;

- Структурен ефект с равнище от 417 души;

- Локален ефект в негативна посока - 129 души.

Относно локалните ефекти можем да заключим, че Добричка област няма конкурентни предимства пред останалите региони, т.е. този сектор не се развива по-добре, отколкото средно за страната. Разпределението на заетостта в отделните сектори на района е по-добра, отколкото е този показател за страната. Може да се приеме, че съществува 
диверсификация на дейностите в областта.

Високите резултати за административните и спомагателни дейности показва, че ангажираността на голяма част от заетите е в областта на услугите и нещо повече, този дял се увеличава през изследвания период. Тук е мястото да отбележим, че подобни изводи трябва да бъдат съпоставени и с други данни за региона и трябва добре да се тълкуват. Така или иначе обаче този анализ, който досега се ползва за научни цели, може да бъде подходящ инструментариум и за изготвяне на стратегии за развитие на областта.

Пространственият ефект с положителни резултати в редица сектори може да бъде основа за привличане на инвестиции извън региона. Още по-сериозни изводи и препорьки относно пространствени различия и конкурентните предимства на региона могат да се очертаят чрез съпоставка на няколко области или статистически райони.В областта на земеделието тази оценка може да допринесе за оценка на влиянието на концентрацията и специализацията на производството върху биологичното равновесие в природата, детайлно разглеждана в [Костадинова,2015, 326].

\section{Заключение}

Както повечето методи за анализ, посочените също не са универсални и не могат да дадат отговори на всички въпроси. Сериозен недостатък на методите е невъзможността да се прогнозират бъдещите изменения в заетостта (Heijman, 1998). При типизацията на регионите с оглед решаване на локализационния избор на предприемачите е необходимо да се включват и допълнителни показатели, освен използваните в класификацията на Камани. По този начин ще се отчита влиянието на по-широк кръг от фактори като образование, развитост на научните изследвания, наситеност с инфраструктура и други.Необходимо е изводите от анализа да бъдат подкрепени с допълнителни изследвания относно потенциала на региона. В противен случай изследователите рискуват да екстраполират настоящите тенденции, което не винаги е оправдано.

\section{Използвана литература / References}

1. Костадинова, Н. Биологичното земеделие в България-необходимост и възможноости. Сборник доклади от юбилейна конференция с международно участие «Агробизнесът и селските райони-настояще и бъдеще». Варна, 2015.стр.326

2. Turlakova, T. Classification and typology of semi-subsistence farm. Nauka-rastudent.ru: Научно-практический журнал, ИП Козлов, 41, 2017, 5.

3. Тонкова,Ст. Локализационния избор, Теоретични подходи и модели за реализация. Изд.Абагар. 2002 г.с.301.

4. Dunn, E.S: A statistical and analytical technique for regional analysis". Papers of the Regional Science Association.1960.vol.6, p.97-112.

5. Fernandez, Matias Mayor, Menendez, Ana Jesus Lopez. The Evolution Of The Employment In The Euro-pean Union. A Stochastic Shift And Share Approach. ERSA, August 27th-31st 2002.

6. Heijman, W.J.M., C.M. van der Heide. Regional Economic Growth And Accessibility: The Case Of The Netherlands. 38th Congress of the European Regional Science Association 28 August -1 September 1998. Vienna

7. Kayne, J, Rural Entrepreneurship Initiative September, Kauffman Center for Entrepreneurial Leadership, 2000,pp.8 